\title{
Untapped aspects of mass media campaigns for changing health behaviour towards non-communicable diseases in Bangladesh
}

\author{
Reshman Tabassum ${ }^{1}$, Guenter Froeschl ${ }^{2,3}$, Jonas P. Cruz ${ }^{4}$, Paolo C. Colet ${ }^{4}$, Sukhen Dey ${ }^{5}$ \\ and Sheikh Mohammed Shariful Islam ${ }^{6,7,8^{*}}$ (i)
}

\begin{abstract}
In recent years, non-communicable diseases (NCDs) have become epidemic in Bangladesh. Behaviour changing interventions are key to prevention and management of NCDs. A great majority of people in Bangladesh have low health literacy, are less receptive to health information, and are unlikely to embrace positive health behaviours. Mass media campaigns can play a pivotal role in changing health behaviours of the population. This review pinpoints the role of mass media campaigns for NCDs and the challenges along it, whilst stressing on NCD preventive programmes (with the examples from different countries) to change health behaviours in Bangladesh. Future research should underpin the use of innovative technologies and mobile phones, which might be a prospective option for NCD prevention and management in Bangladesh.
\end{abstract}

Keywords: Chronic diseases, Health literacy, Behaviour change, Communication, Mass media

\section{Background}

Non-communicable diseases (NCDs) are increasing in epidemic proportion in many developing countries, such as Bangladesh [1, 2]. Evidence suggests a higher agespecific mortality for NCDs among Bangladeshis compared to Western populations, which puts an enormous burden on healthcare systems $[1,3]$. Adopting healthy lifestyles and facilitating behavioural changing tools are key to prevention and management of NCDs [4, 5]. However, a high proportion of Bangladeshi adults have low health literacy, poverty, and lack of knowledge and skills [6, 7]. These people often engross in a veritable sea of healthrelated news from many diverse sources, often without the means to distinguish what is really useful based on grounded or professional evidence and to understand the true significance of the intended messages.

Low health literacy may have adversarial health effects by limiting patients' ability to grasp health information, follow prescribed medical instructions, and communicate

\footnotetext{
* Correspondence: shariful.islam@icddrb.org

${ }^{6}$ Non-Communicable Diseases Initiative, International Center for Diarrhoeal Diseases Research, Bangladesh (ICDDR,B), 68, Shaheed Tajuddin Ahmed Sarani, Mohakhali, Dhaka 1212, Bangladesh

${ }^{7}$ The George Institute for Global Health, University of Sydney, Sydney, NSW, Australia

Full list of author information is available at the end of the article
}

with health professionals and to acquire proper and timely care [8]. Individuals with lower health literacy are more likely to engage in negative health behaviours, such as smoking, drinking, unhealthy diet, taking extra salt [9], and substances abuse and are prone to have poor health, and impaired medication management capacity; leading to uncontrolled chronic conditions [10], increased healthcare costs [11], hospitalisation, and mortality [12].

Mass media campaigns, including newspapers and other printed material, radio, television, billboards, etc., have been recognised as the main source of health information at the individual level [13]. The impact of this coverage on individual's knowledge, perceptions and attitudes are impressive and are useful in disseminating information and forming public opinion; nevertheless, the possibility for distortion from inaccurate information is noteworthy worldwide [14]. Harnessing the benefits of mass media, many countries have been successful in promoting healthy behavioural change programmes and improving health literacy, for example, Meena cartoons in Bangladesh. The Government of Bangladesh has recently stressed on preventing the epidemic of NCDs in Bangladesh [15]. However, the impact of mass media in changing health behaviours for prevention and management of NCDs is not well documented in Bangladesh. 
Hence, this review aims to discuss the role of mass media campaigns for NCDs and the challenges along it, whilst accentuating on NCD preventive programmes (with the examples from different countries) to change health behaviours in Bangladesh. The strategic mass media routes can endorse the development of future NCD prevention and management programmes in Bangladesh.

\section{Main text}

Mass media campaigns have a broad reach and the potential to influence target audiences' attitude towards healthy behavioural changes [13]. Over the preceding years, media campaigns have been striving to deliver health messages with the intention of changing health behaviours amongst defined populations [16]. In Bangladesh, mass media campaigns have been successful in increasing childhood immunisation, and reducing tobacco use and can potentially cover prevention of cardiovascular diseases, diabetes, cancer screening, and other NCDs. Such campaigns have customised health messages in media to reach target groups and to create maximum exposure to consumers, for instance, using broadcast media-television or radio, as well as outdoor media, including billboards, posters, and print media; thus disseminating significant health messages [16]. Disclosure of such health messages is mostly reflexive, resulting from an accompanying consequence of repetitive use of media. Regardless of the magnitude of mass media campaigns in changing health behaviours around the world, the use of mass media for prevention and management of NCDs remains significantly low in Bangladesh.

Health communication campaigns have been incorporating strategies to distribute messages designed-directly or indirectly - to enlighten, influence, and motivate target audiences' attitudes on changing or maintaining healthrelated behaviours. Messages can be conveyed through a range of channels, including traditional mass media (e.g., television, newspapers); digital media, for example, social media (e.g., Facebook, Twitter, web forums); small print media (e.g., posters, brochures); community interactions (e.g., public forums); and personalised communications (e.g., hotline advising). Nevertheless, traditional mass media has prospects to sway individuals unswervingly and to transmit behaviour changing messages quicker than other communication approaches [16].

A variety of mass media campaigns unveils the prospective of being effective in diverse settings. For example, the SunSmart campaign for skin cancer prevention in Australia substantially increased sun protection behaviours among target groups or communities [17]. A previous study on 10 developing countries reported that television ads, which graphically portrayed the health hazards of tobacco use, were likely to be effective among smokers [18]. A decade of anti-tobacco quit campaign with nationally coordinated Quitline service in Australia has led to significantly reduced smoking prevalence among adolescents and adults [19, 20]. The Florida "Truth" campaign used television and radio commercials, along with other media channels to inform the public about harmful effects of tobacco and to promote social penalties for smoking. Furthermore, The Safe Kids campaign is a global campaign that has used mass media to raise consciousness about the importance of wearing helmets and abiding road safety, fire safety, and home safety regulations to preclude injury and deaths. Such health communication campaigns are envisioned to sway decision-making procedures at both discrete and individual levels. Three anticipated outcomes of health campaigns are: lowering the impediments to change; facilitating individuals to embrace healthy lifestyles or to identify unhealthy social customs; and attaching valued sentiments with behavioural changes [16]. However, most of these programmes have been implemented in developed countries.

Many developing nations have also demonstrated successful mass media campaigns to improve health literacy and to change health behaviours. For instance, mass media campaigns for oral rehydration saline and breastfeeding resulted in reduced number of child mortality in Bangladesh [21], and anti-tobacco campaign in Bangladesh and Tongo led to decrease in smoking prevalence [22, 23]. Other examples include, oral cancer awareness campaigns in Malaysia [24], and a nationwide population screening campaign for diabetes in Brazil [25]. A systematic review evaluated 11 mass media campaigns in developing countries for diarrhoeal diseases, immunisation, and nutrition education and reported that mass media-centric campaigns positively influenced healthly behavioural changes among target audiences [21].These studies provide evidence that mass media can successfully change behavioural risk factors associated with NCDs in developing countries and should be integrated into NCD prevention and management programmes in Bangladesh.

Mass media channels are often more cost-effective at reaching people than any other communication methods. A previous systematic review demonstrated that mass media campaigns that were carefully planned and well executed, attained adequate audience exposure; intertwining with other ongoing prevention activities, such as high visibility enforcement [26]. A mass media education campaign for salt reduction was the most cost-effective population based intervention in both Vietnam and Argentina [27, 28]. Another study showed that the cost-effectiveness ratios for a mass media campaign in preventing the onset of smoking was economically more effective compared to other preventive and therapeutic strategies [29].

There is a need to emphasise on developing and monitoring the implementation of health campaigns to ensure that the interventions reach the target population. In 
Table 1 Challenges for mass media in developing countries, including Bangladesh

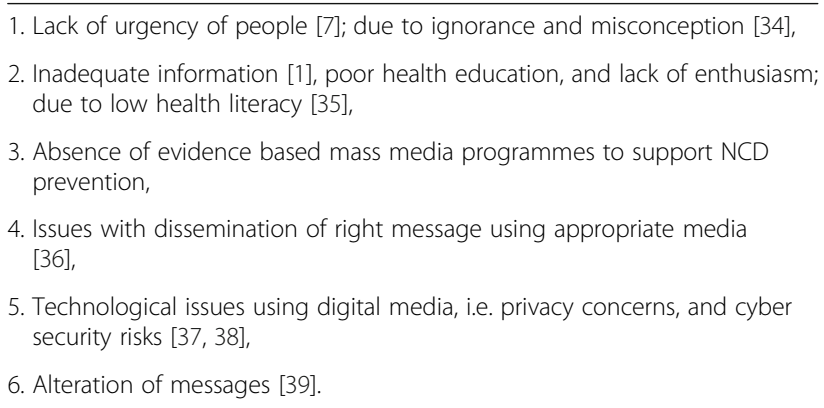

recent years, information technology has played a great role to deliver health information using several technologies, including websites, social media, and mobile phone text messaging [30, 31]. A recent study in Bangladesh unveiled that mobile phone text messaging could reach a large number of patients with type 2 diabetes and could help to improve disease management at low cost $[32,33]$. It is essential to underpin the use of innovative technologies and mobile phones, which might be a prospective option for NCD prevention and management in Bangladesh.

Several challenges impact the successful use of mass media campaigns in developing countries similar to Bangladesh (Table 1).

\section{Conclusion}

Mass media has enormous potential to support healthy behavioural changes and should be integrated into the NCD prevention programmes in Bangladesh. Bangladesh needs to pledge for effective measures through strategic routes, while planning to assimilate additional evidence on preventing and managing NCDs with appropriate mass media channels. Further research on emerging digital technologies necessitates to be explored in developing countries, such as Bangladesh, for changing health behaviour towards NCDs among target population.

\section{Acknowledgements}

We thank Dr. Sun-Young Kim, PhD, Assistant Professor of Global Health, Department of Healthcare Management and Policy, School of Public Health, Seoul National University, South Korea for her valuable comments and support to review this manuscript.

\section{Funding}

None. SMSI is supported by a Postdoc Research Fellowship funded by The George Institute for Global Health, University of Sydney, Australia.

\section{Availability of data and materials}

Not applicable

\section{Authors' contributions}

RT and SMSI contributed to the concept, design and initial drafting of the paper. All other authors provided scientific inputs to improve the drafts. All authors contributed to formulation, drafting, completion, and approval of the final manuscript.

Ethics approval and consent to participate

Not applicable

Consent for publication

Not applicable

\section{Competing interests}

The authors declare that they have no competing interests.

\section{Author details}

${ }^{1}$ Department of Management, Faculty of Business and Law, Deakin University, Melbourne, Australia. ${ }^{2}$ Center for International Health, Medical Center of the University of Munich (LMU), Munich, Germany. ${ }^{3}$ Division of Infectious Diseases and Tropical Medicine, Medical Center of the University of Munich (LMU), Munich, Germany. ${ }^{4}$ Shaqra University, Shaqraa, Saudi Arabia. ${ }^{5}$ Bellamarine University, Kentucky, USA. ${ }^{6}$ Non-Communicable Diseases Initiative, International Center for Diarrhoeal Diseases Research, Bangladesh (ICDDR,B), 68, Shaheed Tajuddin Ahmed Sarani, Mohakhali, Dhaka 1212, Bangladesh. ${ }^{7}$ The George Institute for Global Health, University of Sydney, Sydney, NSW, Australia. ${ }^{8}$ Institute for Physical Activity and Nutrition (IPAN), School of Exercise and Nutrition Sciences, Faculty of Health, Deakin University, Geelong, Australia.

Received: 25 November 2016 Accepted: 9 January 2018

Published online: 18 January 2018

\section{References}

1. Islam SMS, Purnat TD, Phuong NTA, Mwingira U, Schacht K, Fröschl G. Noncommunicable diseases (NCDs) in developing countries: a symposium report. Glob Health. 2014;10(1):81.

2. Bennett DA, Bisanzio D, Deribew A, Gething PW, Hay SI, Ali R. Global, regional, and national under-5 mortality, adult mortality, age-specific mortality, and life expectancy, 1970-2016: a systematic analysis for the Global Burden of Disease Study 2016. Lancet. 2017;390(10100):1084-150.

3. Biswas T, Islam A, Rawal L, Islam S. Increasing prevalence of diabetes in Bangladesh: a scoping review. Public Health. 2016;138:4-11.

4. Arena R, Guazzi M, Lianov L, Whitsel L, Berra K, Lavie CJ, Kaminsky L, Williams M, Hivert M-F, Cherie Franklin N. Healthy lifestyle interventions to combat noncommunicable disease-a novel nonhierarchical connectivity model for key stakeholders: a policy statement from the American Heart Association, European Society of Cardiology, European Association for Cardiovascular Prevention and Rehabilitation, and American College of Preventive Medicine. Eur Heart J. 2015:36(31):2097-109.

5. Biswas T, Islam SMS, Islam A. Prevention of Hypertension in Bangladesh: A Review. Cardiovasc J. 2015;7(2):137-44.

6. Koehlmoos TP, Islam Z, Anwar S, Hossain SAS, Gazi R, Streatfield PK, Bhuiya AU. Health transcends poverty: the Bangladesh experience. Good Health Low Cost. 2011;25:47-81.

7. Islam SMS, Biswas T, Bhuiyan FA, Mustafa K, Islam A. Patients' perspective of disease and medication adherence for type 2 diabetes in an urban area in Bangladesh: a qualitative study. BMC Res Notes. 2017;10(1):131.

8. Nutbeam D. Health literacy as a public health goal: a challenge for contemporary health education and communication strategies into the $21 \mathrm{st}$ century. Health Promot Int. 2000:15(3):259-67.

9. Islam SMS, Mainuddin A, Islam MS, Karim MA, Mou SZ, Arefin S, Chowdhury KN. Prevalence of risk factors for hypertension: A cross-sectional study in an urban area of Bangladesh. Glob Cardiol Sci Pract. 2015;2015(4):43.

10. Kripalani S, Henderson LE, Chiu EY, Robertson R, Kolm P, Jacobson TA. Predictors of medication self-management skill in a low-literacy population. J Gen Intern Med. 2006;21(8):852-6.

11. Islam SMS, Lechner A, Ferrari U, Laxy M, Seissler J, Brown J, Niessen LW, Holle R. Healthcare use and expenditure for diabetes in Bangladesh. BMJ Global Health. 2017;2(1):e000033.

12. Fang MC, Machtinger EL, Wang F, Schillinger D. Health literacy and anticoagulation-related outcomes among patients taking warfarin. J Gen Intern Med. 2006;21(8):841-6. 
13. Randolph W, Viswanath K. Lessons learned from public health mass media campaigns: marketing health in a crowded media world*. Annu Rev Public Health. 2004;25:419-37.

14. Weinreich NK. Hands-on social marketing: a step-by-step guide to designing change for good. 2nd ed. Thousand Oaks: Sage Publications; 2010.

15. Islam SMS, Tabassum R. Implementation of information and communication technologies for health in Bangladesh. Bull World Health Organ. 2015;93(11): 806-9.

16. Wakefield MA, Loken B, Hornik RC. Use of mass media campaigns to change health behaviour. Lancet. 2010;376(9748):1261-71.

17. Montague M, Borland R, Sinclair C. Slip! Slop! Slap! And SunSmart, 19802000: skin cancer control and 20 years of population-based campaigning. Health Educ Behav. 2001;28(3):290-305.

18. Wakefield M, Bayly M, Durkin S, Cotter T, Mullin S, Warne C. Smokers' responses to television advertisements about the serious harms of tobacco use: pre-testing results from 10 low- to middle-income countries. Tob Control. 2011:22(1):24-31.

19. White $V$, Tan N, Wakefield M, Hill D. Do adult focused anti-smoking campaigns have an impact on adolescents? The case of the Australian National Tobacco Campaign. Tob Control. 2003;12(suppl 2):ii23-9.

20. Miller C, Wakefield M, Roberts L. Uptake and effectiveness of the Australian telephone Quitline service in the context of a mass media campaign. Tob Control. 2003;12(suppl 2):ii53-8.

21. Naugle DA, Hornik RC. Systematic review of the effectiveness of mass media interventions for child survival in low- and middle-income countries. J Health Commun. 2014;19(sup1):190-215.

22. Islam SMS, Mainuddin A, Chowdhury KN. Prevalence of tobacco use and its contributing factors among adolescents in Bangladesh. Heart India. 2016;4(3):85.

23. Sugden C, Filiai S, Phongsavan P, Gloede S, Tongamana VO. Developing antitobacco mass media campaign messages in a low-resource setting: experience from the Kingdom of Tonga. Tob Control. 2017;26(3):344.

24. Saleh A, Yang Y-H, Ghani WMNWA, Abdullah N, Doss JG, Navonil R, Rahman ZAA, Ismail SM, Abu Talib N, Zain RB. Promoting oral cancer awareness and early detection using a mass media approach. Asian Pac J Cancer Prev. 2012;13(4):1217-24.

25. Nucci LB, Toscano CM, Maia ALM, Fonseca CD, Britto MMB, Duncan BB, Schmidt Ml. A nationwide population screening program for diabetes in Brazil. Rev Panam Salud Publica. 2004;16(5):320-7.

26. Elder RW, Shults RA, Sleet DA, Nichols JL, Thompson RS, Rajab W, Services TFoCP. Effectiveness of mass media campaigns for reducing drinking and driving and alcohol-involved crashes: a systematic review. Am J Prev Med. 2004;27(1):57-65.

27. Ha DA, Chisholm D. Cost-effectiveness analysis of interventions to prevent cardiovascular disease in Vietnam. Health Policy Plan. 2010; 26(3):210-22.

28. Rubinstein A, Martí SG, Souto A, Ferrante D, Augustovski F. Generalized costeffectiveness analysis of a package of interventions to reduce cardiovascular disease in Buenos Aires, Argentina. Cost Eff Resource Allocation. 2009;7(1):10.

29. Secker-Walker RH, Worden JK, Holland RR, Flynn BS, Detsky AS. A mass media programme to prevent smoking among adolescents: costs and cost effectiveness. Tob Control. 1997;6(3):207-12.

30. Islam SMS, Tabassum R. Implementation of information and communication technologies for health in Bangladesh. Bull World Health Organ. 2015;93(11): 806-9.

31. Chow CK, Ariyarathna N, Islam SMS, Thiagalingam A, Redfern J. mHealth in cardiovascular health care. Heart Lung Circ. 2016;25(8):802-7.

32. Islam SMS, Niessen LW, Ferrari U, Ali L, Seissler J, Lechner A. Effects of mobile phone SMS to ImproveGlycemic control among patients with type 2 diabetes in Bangladesh: a prospective, parallel-group,Randomized Controlled Trial. Diabetes Care. 2015;2015(38):112-3.

33. LA Islam SMS, Ferrari U, Seissler J, Holle R, Niessen LW. Mobile phone use and willingness to pay for SMS for diabetes in Bangladesh. J Public Health. 2016;38(1):163-9.

34. Chia SC, Lee W. Pluralistic ignorance about sex: the direct and the indirect effects of media consumption on college students' misperception of sexrelated peer norms. Int J Public Opin Res. 2008;20(1):52-73.

35. Zarcadoolas C, Pleasant A, Greer DS. Understanding health literacy: an expanded model. Health Promot Int. 2005;20(2):195-203.

36. Riff D, Lacy S, Fico F. Analyzing media messages: Using quantitative content analysis in research. 3rd ed. London: Routledge; 2014.
37. Bertot JC, Jaeger PT, Grimes JM. Using ICTs to create a culture of transparency: E-government and social media as openness and anticorruption tools for societies. Gov Inf Q. 2010;27(3):264-71.

38. O'Keeffe GS, Clarke-Pearson K. The impact of social media on children, adolescents, and families. Pediatrics. 2011;127(4):800-4.

39. Mondal D. Role of media in social change: a case study on rural health in a tribal village of Birbhum district, West Bengal. Int J Phys Soc Sci. 2014;4(4):209.

\section{Submit your next manuscript to BioMed Central and we will help you at every step:}

- We accept pre-submission inquiries

- Our selector tool helps you to find the most relevant journal

- We provide round the clock customer support

- Convenient online submission

- Thorough peer review

- Inclusion in PubMed and all major indexing services

- Maximum visibility for your research

Submit your manuscript at www.biomedcentral.com/submit
) Biomed Central 